\title{
Towards a Methodology for the Development of Integrated IT Infrastructures
}

\author{
Marinos Themistocleous and Zahir Irani \\ School of Information Systems, Computing and Mathematics \\ Information Systems Evaluation and Integration Network Group (ISEing) \\ Brunel University, Uxbridge, UB8 3PH, UK \\ \{Marinos.Themistocleous; Zahir.Irani\}@brunel.ac.uk
}

\begin{abstract}
In this paper, the authors propose and validate a methodology for the development of integrated Information Technology (IT) infrastructures. The motivation for putting forward a new methodology is grounded on the limitations of the various software engineering methodologies (traditional) that exist today. Despite that the traditional methodologies result in the development of Information Systems (IS) from scratch, Enterprise Application Integration (EAI) builds integrated IT infrastructures using existing applications. This significant difference is associated with many issues needed to be realised and addressed like: (a) the changes that such an infrastructure brings to organisations, (b) the resistance to change and (c) the extension of IS lifecycle's. The proposed methodology consist of eight stages and aims at supporting software engineers, organisations and researchers to build integrated IT infrastructures. As a result the methodology seeks to contribute to the body of knowledge.
\end{abstract}

Keywords: EAI, Software Engineering

\section{Introduction}

Since the early days of Information Systems (IS) implementations, applications have been built using software engineering techniques. Among others, methodologies such as the Soft System Methodology (SSM), Structured Systems Analysis and Design Method (SSADM), Information Systems Development Life Cycle (SDLC), have been used to guide the development of software solutions [1]. Most of these methodologies ${ }^{1}$ (traditional) have been excessively usefull and supported organisations to construct their Information Technology infrastructures.

Despite that they have provided significant benefits, they have many limitations. Nonetheless, it is not the intension of this paper to discuss and analyse these limitations as there is a high volume of articles and books investigating these issues. This paper

\footnotetext{
${ }^{1}$ For the purpose of this paper the authors refer to these methodologies using the term 'traditional'.
}

attempts to move the research on software engineering a step forward. It focuses on the emerging area of Enterprise Application Integration, and proposes a methodology for the development of integrated IT infrastructures. The necessity for researching this area has been highlighted in the literature [2-4]. In particular Themistocleous et al., [5] reported that from a software engineering perspective, it would be critical to understand how engineers develop integrated infrastructures. They also highlighted that there is a need to identify and analyse the main stages in this software development process.

This paper seeks to respond to these two issues. Initially, the paper introduces EAI and explains its differences comparing to other software development tools and technologies. Once the differences among EAI and the traditional IS development projects are analysed, the proposed methodology is brought forward. Thereafter, the section 4 describes the research design with the following sections presenting and discussing the empirical data and findings. Implications for practice and conclusions are then drawn.

\section{Enterprise Application Integration}

Enterprise Application Integration has been emerged to piece together intra and inter-organisational systems. Unlike other technologies, EAI integrates different types of software like custom applications, packaged systems and e-business solutions. EAI results in the development of flexible and maintainable solutions by incorporating functionality from disparate applications. One of the biggest differences among EAI and other technologies is that the former achieves process integration. However, the key to success is still the degree to which the business process is supported seamlessly both from technical and behavioural perspectives [6].

From a business perspective EAI results in the reduction of overall integration cost due to the decrement of both integration time and maintenance costs [7]. Also, EAI achieves ROI as it provides a flexible, manageable and maintainable IT infrastructure that supports the changing business and technical requirements. Based on an integrated enterprise 
architecture, organisations can increase their productivity, provide better services and improve the relationships with their collaborators [8]. Moreover, EAI supports strengthened supply chains and improves collaboration between organisations and suppliers. Other benefits include the provision of a centralised point of control, faster time to marketing and increased market share.

Since the appearance of EAI, there has been a lot of confusion regarding its: (a) scope, (b) nature and (c) level of applicability, with the literature explaining all these issues [2, 9, 10]. Recently more confusion has been come along as many consultants and researchers support that web services is an alternative to EAI. This issue should be clarified as a survey conducted in UK illustrates that $56 \%$ of EAI projects are based on web services [11]. It is therefore proved that web services are not an alternative to EAI technology but a significant part of it. To stem further misinterpretations of EAI, the authors define Enterprise Application Integration as the:

'Structured Application of Technologies,

Tools, Methods, Approaches and Plans to

deliver end to end integrated business processes running on IT infrastructures.'

Such a definition indicates that EAI is not only an umbrella term of technologies such as application servers, message brokers, and web services. It also consists of approaches (e.g. strategic or opportunistic application of EAI [12]), methods (e.g. data-centric, process-centric [13]) and tools (e.g. integration engines [14]) that are applied in a structured way to integrate business processes and IT infrastructures. As reported in the previous section, this paper focuses more on this structured way that EAI is applied to achieve integration. Before analysing this issue, it would be better to present the differences between EAI projects and tradition software projects.

Lam [3] supports that EAI projects have many significant differences comparing to other software development projects. The primary reason of using EAI is not to build a system from scratch but to piece together multiple incompatible and in many cases heterogeneous applications. Therefore, the emphasis is on the integration of existing systems and not on the construction of new one.

Another difference is that EAI projects bring a chain of organisational changes in terms of structure, control (e.g. process control) and workflow. These changes are deeper comparing to the traditional software projects as they impact multiple systems, departments and employees. An example of this is the case of a multinational petroleum organisation where the EAI solution resulted in a dramatic reduction of information systems on use. In particular, from the 2640 applications that operated before the EAI adoption, only $10 \%$ remained on place at the end of EAI project. With no doubt, such a dramatic change has a heavy impact on the organisation and employees [15].

To the best of the authors' knowledge, despite the plethora of software engineering methodologies that exist for the development of traditional projects, there is a lack of established methodologies for EAI. Given the increasing attention to EAI implementations, and the suggestions made on this issue, by academics $[3,5]$ and practitioners [16], it is time to further investigate this topic.

\section{Towards the Development of an EAI Methodology}

Lam and Shankararaman [4] were the first who proposed a methodology for EAI. Their approach, called Entrerprise Integration Methodology (EIM), consists of the five stages that are summarised in Table 1 .

EIM methodology has contributed to this area as it underlines the importance of understanding business processes when integrating systems. It also stresses the need to map processes on existing software solutions. Despite its contribution, EIM has limitations that need to be addressed. For instance EIM does not touch issues like systems' restructuring or the new software solutions that need to be developed.

\begin{tabular}{|l|l|}
\hline \multicolumn{1}{|c|}{ Stage } & \multicolumn{1}{|c|}{ Description } \\
\hline $\begin{array}{l}\text { Understand } \\
\text { the end-to- } \\
\text { end business } \\
\text { process }\end{array}$ & $\begin{array}{l}\text { Since EAI integrates business } \\
\text { processes, it is importand that } \\
\text { organisations understand their } \\
\text { business processes. }\end{array}$ \\
\hline $\begin{array}{l}\text { Map the } \\
\text { process onto } \\
\text { components }\end{array}$ & $\begin{array}{l}\text { The focus here is on mapping the } \\
\text { processes on existing software } \\
\text { components. }\end{array}$ \\
\hline $\begin{array}{l}\text { Derive the } \\
\text { requirements }\end{array}$ & $\begin{array}{l}\text { This stage deals with the integration } \\
\text { requiments }\end{array}$ \\
\hline $\begin{array}{l}\text { Produce the } \\
\text { architecture }\end{array}$ & $\begin{array}{l}\text { Based on the previous stage the } \\
\text { intergation architecture is produced }\end{array}$ \\
\hline $\begin{array}{l}\text { Plan the } \\
\text { integration }\end{array}$ & $\begin{array}{l}\text { This is the actual plan for } \\
\text { implementing the integrated } \\
\text { architecture }\end{array}$ \\
\hline
\end{tabular}

Table 1: The EIM Methodology [4]

In an attempt to overcome the limitations of EIM the authors introduce a new methodology. The proposed methodology consists of the following eight stages: (a) Planning, (b) Scenarios Building and Evaluation, (c) Business Process Reengineering, (d) Systems Restructuring, (e) Requirements Analysis, (f) Filling the Gap with New Systems Develoment (g) Integration and Testing (h) Operation and Mainenance. These stages are explained below:

- Stage I - Planning: Before organisations take a decision for implementing an EAI solution, they need to understand and evaluate all the parameters associated with such a project. In studying this area, Themistocleous [17] proposed and validated a set of ten factors that influence the decision 
making process for EAI adoption. These factors are the: (a) costs, (b) benefits, (c) barriers, (d) internal pressures, (e) external pressures, (f) support, (g) IT infrastructure, (h) IT sophistication, (i) evaluation framework for the assessment of integration technologies and $(\mathrm{k})$ evaluation framework for the assessment of EAI packages. All these factors should be considered as part of the feasibility study that is taking place in this stage. For instance, it is extremely important that organisations understand all the different parameters associated with the cost of an EAI solution (e.g. software, hardware, training, cost of change etc). Also, the organisations need to assess the perceived benefits or the possible barriers that come up from such a project.

- Stage II - Scenarios Building and Evaluation: After the decision for an EAI solution, organisations need to develop and evaluate a range of possible scenarios. The literature suggests that organisations follow two different approaches when applying EAI [12]. The first one is the opportunistic approach in which enterprises use EAI to overcome integration problems on specific processes or departments. The second one (strategic approach) requires end-to-end application of EAI in organisation. The latter is associated with dramatic changes in organisations as the majority of the business processes should be integrated. Depending on the approach the organisations select, they need to build multiple integration scenarios and test them using simulation tools. This stage is relevant to the first stage of EIM methodology in terms that among others end-to-end business process understanding is required.

- Stage III - Business Process Reengineering: Unlike other software packages and technologies that support generic business processes (e.g. ERP systems) EAI results in the automation and integration of customised processes. Thus, many organisations tend to reengineer their processes when introducing an EAI solution to improve their performance and gain competitive advantage. As a result, the majority of organisations spend a lot of time and money on Business Process Reengineering (BPR). The BPR takes place after the scenarios building and evaluation. Based on these scenarios organisations need to change their processes to run their business on their own way and not on the way that some software packages dictate them. As a result the majority of EAI projects involve BPR as EAI supports organisations to automate and integrate the business processes in the way they like. Similar to the previous stage, end-to-end business process understanding is required too.

- Stage IV - Systems Restructuring: Enterprise Application Integration is not about linking all the existing systems together. It is about integrating these systems in a way that it is flexible, manageable and maintainable. This means that there is no need to run multiple applications that do the same job or storing the same data. A major goal in EAI projects is to reduce the redundancy of data and applications. Thus, software solutions have to be phased out, data should be migrated and many data sources should be merged or eliminated. An important step in this stage is to map the process onto existing components and applications as Lam and Shankararaman [4] suggested. Another critical step is to clear and migrate data as well as to phase out all the unnecessary systems without causing problems to the performance of the organisation.

- Stage V - Requirements Analysis: From the previous stage, organisations have a better view regarding the gaps in their IT infrastructure and the new applications that are required to fill these gaps or replace legacy systems. Also, following the: (a) Scenarios' Building and Evaluation, (b) Business Process Reengineering and (c) Systems Restructuring stages, the requirements for the integration of the IT infrastructures are now more clear. Thus, in this stage, the analysis of these requirements is taking place in a similar way to one proposed by other methodologies in the literature such as SSADM [1]. However, this stage does not only focus on the requirements analysis, but also on the evaluation of the appropriate technologies and tools for integration. For that reason, it is suggested that organisations should make use of the evaluation frameworks proposed in the literature for the assessment of these technologies [9, 17, 18]. The literature supports that it is critical to evaluate the integration technologies and tools before the actual implementation of EAI project as there are so many differences in the qualities, functionality the level and type of integration that these technologies and tools achieve.

- Stage VI - Filling the Gap - New Systems Development: This stage deals with the analysis and the development of those applications that are required to complete the IT infrastructure. After the end of the Requirements Analysis stage, organisations know exactly: (a) the gaps in their IT infrastructure and (b) those processes that are not fully automated (at both intra and interorganisational level). Also, they are aware of those legacy systems that need to be replaced. Thus, in this stage organisations analyse, design, implement and test all these systems. In doing so, they can use any kind of software engineering methodology that is available and suits their needs. Some issues explained by Lam and Shankararaman [4] in their methodology (Derive the Requirements stage) can also be applied here. 
- Stage VII - Integration and Testing: The actual integration of the IT infrastructure should start, once the applications (that partially or fully automate business processes) are on place. This stage can also start before the end of the previous one as not all software solutions are required to be available at the same time. Thus, organisations can safe time by starting integrating their systems before the completion of all the new applications. What they have to make clear is that all the solutions that are related with one process should be available before starting integrating this process. During this stage, integrators build the four layers of the integration infrastructure [19] using a hub and spoke architecture or any other variation of it $[14,20]$. Also, they create the interfaces among the applications and the integration infrastructure as well as design and implement any adapters needed. Last but not least, the integrators need to test their solutions to check if end-to-end integration is achieved in a secure and flexible way. Techniques reported in the literature for testing the systems should also be employed [1].

- Stage VIII - Operation and Maintenance: The last stage of the methodology refers to the operation and the maintenance of the integrated IT infrastructure. As reported by Irani et al., [2], EAI has extended the systems' lifecycles, and thus, it is no clear when systems expire. For that reason, it is important to focus on the maintenance of these systems and do any additional changes to retain integrated nature of the IT infrastructure. Techniques reported in the normative literature can also be used during the operation and maintenance stage. The proposed methodology is illustrated in Figure 1.

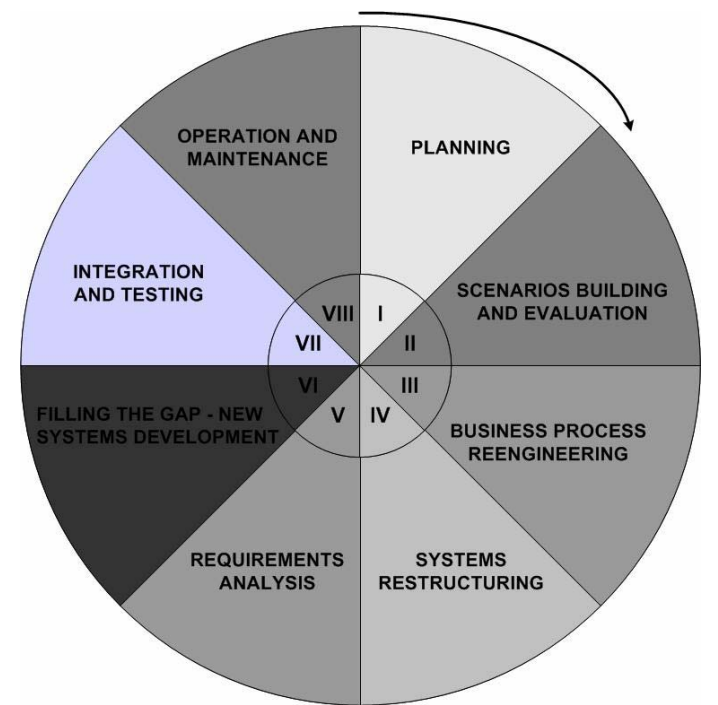

Figure 1: The Proposed Methodology

\section{Research Design}

An interpretive, qualitative multiple case study strategy was selected to conduct this research. Interpretitivism stance was opted as the aim of this paper is to understand how organisations implement EAI solutions as well as to find out what are the main stages in this procedure. An interpretivism stance allows the authors to navigate and better explain this phenomenon in the organisational setting. Also, the authors suggest that in the context of this research a qualitative approach is more appropriate as such approach can be used to: (a) investigate little-known phenomena like implementing EAI solutions, (b) examine in depth complex processes, (c) examine the phenomenon in its natural setting and, (d) learn from practice. A multiple case study strategy was employed to explore and understand these issues underlined above [21]. In doing so, various data collection methods such as interviews, documentation, and observation were used. The bias that is considered to be a danger in using qualitative research approach was overcome in this research through data triangulation. The use of multiple data collection methods makes the triangulation possible which provides stronger substation of theory [22]. For the purpose of this paper, three types of triangulation were used namely: (a) data [23]; (b) methodological and, (c) interdisciplinary triangulation [24].

\section{Empirical Data and Discussion}

After proposing the methodology, presented in section 3 , the authors conducted multiple case studies in 12 organisations and interviewed the various stakeholders involved in the EAI project. The interviews lasted for about 40 minutes. The details of the case organisations and the number of the interviewees are presented in Table 2. The empirical data collected from these organisations are presented and Table 3 and discussed below. In Table 3, the

symbols $\odot, \ominus$ and $\bullet$ represent the values low, medium and high following a similar scale to the one used by Miles and Huberman [25]. In addition, the symbols $\checkmark$ and $\boldsymbol{x}$ are used to show whether an organisation has followed a specific stage $(\checkmark)$ or not $(\boldsymbol{x})$. The letters $\mathbf{S}$ and $\mathbf{O}$ are used in the second column to represent the Strategic and Opportunistic approach respectively. Table 2 shows (from the left to the right) the: (a) type of organisation, (b) the organisation (for some of them coded names are used due to confidentiality reasons), (c) the stages of the proposed methodology, (d) the use of evaluation frameworks (by the case organisations), (e) the number of pilot EAI projects taken place and (f) the implementation (or not) of a full scale (actual) EAI project by the organisations. 
Case

Description

No Company

Company Description

Number of Interviews

OILCORP is a multinational petroleum company with more than 100,000 employees operating in more than

1 OilCorp 135 countries worldwide. The company is organised into five core business divisions including oil, gas and power, chemicals, renewable and, exploration and production.

AutoCorp is a multinational organisation that traditionally operates in the automotive sector. It has up to 200.000 employees in 132 countries and has an annual turnover of $€ 31.6$ billions. The organisation consists

2 Autocorp of 250 subsidiaries and affiliated companies in 50 countries. AutoCorp has 185 production plants worldwide, with 43 of them located in its home-country with the rest remaining in Europe, Africa, Asia, Australia and North and South America.

SPORT Corp is a multinational organisation operating in the sports industry for the past 35 years. It operates

3 SportCorp in more than 150 countries and employs more than 25,000. The main key operations are production,

\begin{tabular}{l|l} 
marketing and sales. The company has an annual turnaround of $\$ 3.87$ billions. \\
\hline $\begin{array}{l}\text { WEST-HOSPITAL is an acute NHS trust, employing more than } 3,000 \text { staff across two sites. The trust along } \\
\text { with } 72 \text { primary healthcare services providers and six rehabilitation units, provides services to the local }\end{array}$
\end{tabular} with 72 primary healthcare services providers and six rehabilitation units, provides services to the local

4 West UK population of over 260,000 persons. The main hospital has 638 beds and provides acute healthcare services and the other hospital with 103 beds provides mainly the rehabilitation services. The trust treats over 60,000 in-patients and day cases, approximately 204,000 outpatients and 70,000 Accident and Emergency patients each year.

5 Central CENTRAL-HOSPITAL is one of the UK's old foundation trusts. It was established in 1805. With the

5 London formation of the NHS in 1948 it lost its status as a voluntary hospital. It has more than 1200 employees on 11 different sites in and around UK, with teaching and research institute.

$6 \begin{aligned} & \text { North West } \\ & \text { UK }\end{aligned}$

NWE-HOSPITAL hospital serves a population of approximately 360,000 persons and is located in the northwest of England. The main hospital is split on three sites, along with 65 primary healthcare services

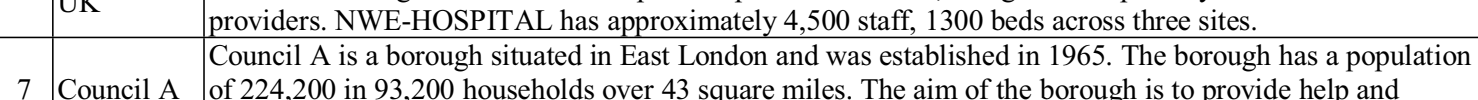

7 Council A of 224,200 in 93,200 households over 43 square miles. The aim of the borough is to provide help and

\begin{tabular}{|l|l|l} 
& information as efficiently and quickly as possible to its citizens. \\
\hline & & Council B is council that lies in the wide area of London. It includes principal areas of government,
\end{tabular}

8 Council B shopping, entertainment and tourism, professional organisations and residential areas. According to the 2001 census the borough had a population of 181,279.

Council C is situated in the North-east of London and has an area of 1,898 hectares and a population of 202,819. The strategic plan for Council C by 2014, is to improve the quality of life in the borough, increase public and voluntary agencies and to provide higher quality, accessible and responsive services and facilities.

Sen-Kung Technologies Ltd set up the company since 1979 and mainly produces PCB Board. It has 60

9 Council C

$10 \begin{aligned} & \text { Sen-Kung } \\ & \text { Ltd }\end{aligned} \begin{aligned} & \text { Sen-Kung Technologies Ltd set up the company since } 1979 \text { and mainan and its capital is US\$1.51millions in 2004. The organisation affiliated companies } 4 \\ & \text { countries. Sen-Kung not only provides good quality electronic products to the main IT companies and very }\end{aligned}$ professional in $\mathrm{R} \& \mathrm{D}$ persuasion but also receive many credibility from the customers. The main products of Sen-Kung are divided into two business units sectors: PCB Board and LCD monitor Board.

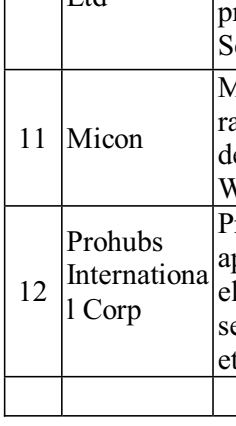

Micon Technology corporation set up since 1993. The capital of Micon is US\$142,850 in the first year and raised to $\$ 1.7$ millions in 2002. There are 20 employees in Micon Taipei. The organization includes 3 main departments and mainly focuses on R\&D development in company's strategy. Micon's main customers are Weltrend, Myson Century, Trumpion Microelectronic and TOPRO.

Prohubs International Corp founded in 1995. Prohubs is excellent agent in equipment of computer application such as electronic components, mobile communications, personal digital equipment, household electronics, semiconductor and material of Photoelectron Application. Prohubs provides professional services to main semiconductor manufacturing and IC design companies such as SIGMATEL, C-MEDIA etc. Prohubs employs 40 persons in Taiwan.

Table 2: Description of Case Organisations 


\begin{tabular}{|c|c|c|c|c|c|c|c|c|c|c|c|c|}
\hline & & \multicolumn{8}{|c|}{ STAGE } & \multirow[b]{2}{*}{$\begin{array}{c}\text { Evaluation } \\
\text { Framework } \\
\end{array}$} & \multirow[b]{2}{*}{$\begin{array}{c}\text { Pilot } \\
\text { Projects }\end{array}$} & \multirow[b]{2}{*}{$\begin{array}{l}\text { Actual } \\
\text { Project }\end{array}$} \\
\hline $\begin{array}{c}\text { Type of } \\
\text { Organisation }\end{array}$ & Organisation & I & II & III & IV & $\mathbf{V}$ & VI & VII & VIII & & & \\
\hline \multirow{3}{*}{$\begin{array}{c}\text { Large } \\
\text { Organisations }\end{array}$} & Oil_Corp & $\bullet$ & $\mathrm{S}$ & $\bullet$ & • & $\checkmark$ & $\bullet$ & $\checkmark$ & $\checkmark$ & $\checkmark$ & 4 & $\checkmark$ \\
\hline & Auto_Corp & $\bullet$ & $\mathrm{S}$ & $\bullet$ & $\bullet$ & $\checkmark$ & ○ & $\checkmark$ & $\checkmark$ & $\checkmark$ & 2 & $\checkmark$ \\
\hline & Sports_Corp & $\bullet$ & $\mathrm{O}$ & $\bullet$ & $\bullet$ & $\checkmark$ & $\ominus$ & $\checkmark$ & $\checkmark$ & $\checkmark$ & 3 & $\checkmark$ \\
\hline & & & & & & & & & & & & \\
\hline \multirow{3}{*}{ Hospitals } & West_UK & $\bullet$ & $\mathrm{O}$ & e & $\ominus$ & $\checkmark$ & 0 & $\checkmark$ & $\checkmark$ & $\checkmark$ & 2 & $\checkmark$ \\
\hline & Central London & 0 & $\mathrm{O}$ & $x$ & ○ & $\checkmark$ & $x$ & $\checkmark$ & $\checkmark$ & $\checkmark$ & 1 & $x$ \\
\hline & North_West_UK & 0 & $x$ & $\ominus$ & $\ominus$ & $\checkmark$ & 0 & $\checkmark$ & $\checkmark$ & $x$ & 1 & $x$ \\
\hline \multirow{3}{*}{$\begin{array}{c}\text { Public } \\
\text { Organisations }\end{array}$} & Council_A & 0 & $x$ & 0 & $x$ & $\sqrt{ }$ & $x$ & $\checkmark$ & $\checkmark$ & $x$ & 1 & $x$ \\
\hline & Council_B & 0 & $\mathrm{O}$ & e & $\bullet$ & $\checkmark$ & 0 & $\checkmark$ & $\checkmark$ & $x$ & 1 & $x$ \\
\hline & Council_C & $\bullet$ & $\mathrm{S}$ & 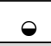 & 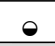 & $\checkmark$ & 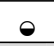 & $\checkmark$ & $\checkmark$ & $\checkmark$ & 1 & $\checkmark$ \\
\hline & & & & & & & & & & & & \\
\hline \multirow{3}{*}{$\begin{array}{l}\text { Small and } \\
\text { Medium } \\
\text { Enterprises }\end{array}$} & Sen-Kung Ltd & 0 & $\mathrm{O}$ & $x$ & $x$ & $\checkmark$ & $x$ & $\checkmark$ & $\checkmark$ & $x$ & 1 & $\checkmark$ \\
\hline & Micon & $\bullet$ & $\mathrm{O}$ & $x$ & $x$ & $\checkmark$ & $x$ & $\checkmark$ & $\checkmark$ & $x$ & 1 & $\checkmark$ \\
\hline & \begin{tabular}{c|} 
Prohubs \\
International Corp
\end{tabular} & $\bullet$ & $\mathrm{S}$ & $x$ & $x$ & $\checkmark$ & $x$ & $\checkmark$ & $\checkmark$ & $x$ & 1 & $\checkmark$ \\
\hline
\end{tabular}

Table 3: Emprical Findings

- Stage I - Planning: The empirical data validate this stage as part of the methodology as all the organisations spent time on planning their project. The fact that all of them run pilot EAI projects proves that organisations required sufficient evidences to proceed to an EAI project. The majority of the project managers reported that they could not undertake an EAI project without measurable evidences. Thus, the investigation of all these issues related to the costs, benefits, barriers, pressures etc was critical for them. Those organisations that did not proceed to the implementation of an EAI project after the end of a pilot; they replied that this has not happened yet due to financial reasons. It is worth noting that all these organisations are waiting the central government or the health authorities to fund the project. When the authors asked the interviewees to comment on the time they spent at this phase, the responses varied covering all ranges of answers (low, medium, high). From the data analysis it appears that there were differences on the level of IT sophistication and understanding in each organisation. For instance those organisations with higher level of IT sophistication spent more time as they well understood the problem they were trying to solve. Thus, they allocated sufficient time in each activity of this phase. This is an interesting finding that validates previous research on this area [5]. It should be noted that the current evidence is stronger as it derives from 12 organisations of different types, sectors and size.
- Stage II - Scenarios Building and Evaluation: The empirical data support that 10 out of the 12 organisations built integration scenarios and assessed them. Four of these organisations focused on a strategic approach of EAI. It is worth noting that all these 4 organisations reported high (detailed) levels of planning and integrated their IT infrastructures (actual EAI project) after the pilots. Interviewees from these organisations mentioned that they considered a strategic approach as it allows them to gain competitive advantage. This finding is also in line with the normative literature [26]. Two organisations did not design any scenarios. The same organisations reported low levels of planning and avoided to use an evaluation framework for the assessment of integration technologies and packages. From the interviews it was revealed that this is related to the low level of IT sophistication.

- Stage III - Business Process Reengineering: The empirical findings validate that the majority ( 8 out of 12) of organisations reengineered their processes when implemented an EAI solution. It appears that all the Small and Medium Enterprises (SMEs) of this research did not redesign their processes. Some of the interviewees mentioned that there was not real need to do so as they were happy from the way they run their processes. The other organisation that skipped BPR did not implement an EAI system at the end. This indicates that a possible implementation of an actual EAI system might require some kind of business process reengineering. Nonetheless, 89 out of the 131 interviewees reported they have to 
keep a low level of BPR as it takes a lot of time and causes many changes. This finding is similar to those reported in the literature [3, 4].

- Stage IV - Systems Restructuring: It appears that this stage is validated from the sample companies as 8 out of 12 organisations restructured their IT infrastructures during the implementation of the pilot or the actual EAI project. The SMEs that were studied here did not restructure their systems. When a manager working for an SME was asked to justify this decision he responded that there is nothing to restructure. We have few systems and all of them are vital for our IT infrastructure'.

- Stage V - Requirements Analysis: All the organisations went through this stage as it was considered as significant for the implementation of their integrated IT infrastructures. Most of the integrators responded that they followed the typical steps when for requirement analysis (similar to other methodologies).

- Stage VI - Filling the Gap - New Systems Development: The empirical data revealed that there is a possible relationship between this stage and the BPR. For instance the same organisations that skipped the BPR stage, did not proceed to the development of new systems. Three of these organisations were the SMEs that were examined in this study. These SMEs mentioned that there was no need to design and implement new systems as they were happy from the functionality of the existing one. The remaining organisations that skipped this stage did not proceed to the implementation of an actual EAI system. When the authors asked the IT managers of these organisations they reported that for the purposes of their pilot EAI projects there was no need to develop any kind of a new solution. Nonetheless, they suggested that for the implementation of the actual system they have to build new applications to fill their gaps as not all of the processes are automated.

- Stage VII - Integration and Testing: All organisations followed this stage. Interviewees were asked to report the percentage of the time they spent on integration and testing. Based on the results it seems that an average time for the integration and testing varies from $30-45 \%$ of the overall time, depending on the complexity, the type and the level of integration. These findings validate previous research on this topic which suggests that the typical times for integration are among 30-40\% [26].

- Stage VIII - Operation and Maintenance: This stage is typical for the methodologies and it is also validated from this research. All organisations followed this stage after the end of their pilot or the actual EAI projects. Figure 2 illustrates few of the important stages of this methodology. As it is shown, after the evaluation of the scenarios, the organisations phased out the redundant systems and developed new solutions to fill their gaps. Finally they pieced all these systems by creating an integrated IT infrastructure.

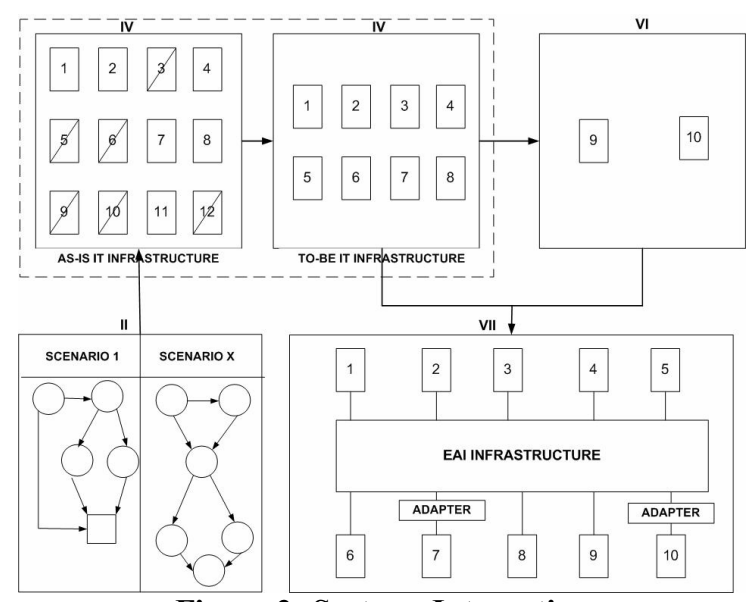

Figure 2: Systems Integration

\section{Lessons Learned}

The findings derived from the case data presented above are to an extent consistent with the findings from previous studies. Thus, the results of this paper provide greater confidence and an understanding of EAI development process which is not case specific. This is of high importance as the data presented and analysed in this article came from 17 different organisations. Although, the findings can not be generalised due to the sample size, they are highlighted to allow other researchers to compare their results with those presented herein. The analysis of the case data indicates that the following lessons learned from this research:

- High level of Planning is required before implementing the actual EAI system: Empirical evidences suggested that those organisations undertaken a detailed planning proceed to the development of the actual EAI system. High levels of planning allow organisations to consider all the factors associated with the adoption of EAI. It is during this stage that organisations measure the possible impact of an EAI solution and take decisions regarding the implementation of the actual EAI project.

- Pilot systems: All organisations run pilot EAI systems before take the decision to fully integrate their IT infrastructures. The explanation for this is twofold: (a) there was a lack of expertise, knowledge and skills in the majority of cases since EAI is relatively a new technology. Therefore, organisations initially preferred to start from an exploratory small pilot project to test the applicability of EAI. (b) The development of EAI solutions is related to high expenditures and brings 
a lot of organisational and structural changes. As a result, organisations chose to implement pilot projects to evaluate the impact of EAI solutions before taking any decision for further implementations.

- IT sophistication is important for the project success: It appears that high levels of IT sophistication are required to proceed to a successful EAI implementation. All the organisations that reported high levels of planning (Stage I) they proceed to the development of the actual EAI project. These organisations reported that before proceeding to the implementation they needed to understand all the different technical and business parameters affecting the project. Clearly the former is related to high levels of IT sophistication. In one case, the extremely low level of IT sophistication resulted to marginal success. In that case, the project was saved the last moment due to the actions of an external consultant who had good knowledge of EAI (high level of IT sophistication).

- Actions at Stages III are related to actions at Stages IV and VI. The findings illustrate that those organisations underestimated the stage III (Business Process Reengineering), they skipped the stages Systems Restructuring and Filling the Gap. It appears that there is a strong relationship among these stages which indicates that decisions at stage III have an impact on stages IV and VI. Also, from the results it appears that these three stages are possibly not so important for small projects taking place at SMEs. However, further research is required on this issue

\section{Conclusions}

This paper focuses on an emerging area dealing with Enterprise Application Integration. Although there are plenty of articles in the literature discussing the nature, benefits and barriers of EAI, there are limited refences on the methodologies that are used to deploy

\section{References}

[1] Avison, D. and G. Fitzgerald, Information Systems Development: Methodologies, Techniques, and Tools. Third Edition ed. 2003, London, UK: McGraw Hill.

[2] Carrier, L., Managing at Light Speed. IEEE Computer, 1999. July(1999): p. 107-109.

[3] Denzin, N.Y.K., The Research Act: A Theoretical Introduction to Sociological Methods. 1978, New York, USA: McGraw Hill.

[4] Eisenhardt, K.M., Building Theories from Case Study Research. Academy of Management Review, 1989. 14(4): p. 532-550.

[5] Irani, Z., M. Themistocleous, and P.E.D. Love, The Impact of Enterprise Application Integration
EAI applications and integrate IT infrastructures. Previous research on this area has highlighted the need for the development of a specific EAI methodology as the traditional methodologies are not sufficient for this kind of applications. One of the major differences is that the traditional software methodologies deal with the development of new systems from scratch where EAI uses existing applications to build an integrated IT infrastructure. Thus, there is a need for a methodology responds to the requirements of EAI tecnology.

Enteprise Integration Methodology is the first attempt for an EAI methodology proposed in the literature. EIM was presented and evaluated herein with the authors regognising its contribution and highlighting its limitations. Using their experiences from researching this area for six years and the normative literature, the authors propose a software engineering methodology that addressed the limitations of the EIM methodology. The proposed methodology consists of eight stages namely: (a) Planning, (b) Scenarios Building and Evaluation, (c) Business Process Reengineering, (d) Systems Restructuring, (e) Requirements Analysis, (f) Filling the Gap with New Systems Development (g) Integration and Testing and (h) Operation and Maintenance.

The proposed methodology has been validated through the practical arena. Empirical data from 12 case studies were summarised to demonstrate that in these cases organisations followed (in the majority of cases) the aforementioned stages when integrating their IT infrastructures. Since, the results are coming from only 12 case studies, they can not be generalised. For that reason more in depth research is required in this area to further investigate this phenomenon. Future research on this area should also be focused on the role of the stakeholders during the implementation of an integrated IT infrastructure as EAI brings a lot of change in organisations. on Information System Lifecycles. Information and Management, 2003. 41(2): p. 177-187.

[6] Janesick, V., The choreography of qualitative research design, in Handbook of qualitative research, N.Y.K. Denzin and Y.S. Lincoln, Editors. 2000, Sage publications: Thousand Oaks, CA. p. 379-399.

[7] Lam, W., Investigating Success Factors in Enterprise Application Integration: A Case Driven Analysis. European Journal of Information Systems, 2005. 14(2): p. 175-187.

[8] Lam, W. and V. Shankararaman, An Enterprise Application Integration Methodology. IT Professionals, 2004. 6(1): p. 40-48. 
[9] Lee, J., K. Siau, and S. Hong, Enterprise Integration with ERP and EAI. Communications of the ACM, 2003. 46( 2): p. 54-60.

[10] Linthicum, D., Enterprise Application Integration. First ed. 1999, Massachusetts, USA: AddisonWesley. 377.

[11] Linthicum, D., B2B Application Integration. first ed. 2000, Massachusetts, USA: AddisonWesley. 408.

[12] Miles, M.B. and A.M. Huberman, Qualitative Data Analysis: An Expanded Sourcebook. 1994, Newbury Park, California, USA: Sage publications.

[13] Puschmann, T. and R. Alt. Enterprise Application Integration - The Case of the Robert Bosch Group. in the 34th Hawaii International Conference on System Sciences. 2001. Maui, Hawaii, USA.

[14] Ring, K. and N. Ward-Dutton, Enterprise Application Integration: Making the Right Connections. First ed. 1999, London, UK: Ovum Ltd. 276.

[15] Ruh, W., F. Maginnis, and W. Brown, Enterprise Application Integration: A Wiley Tech Brief. 2000, New York, USA: Wiley John Wiley \& Sons Inc.

[16] Schmidt, J., EAI Methodology Call to Action. 2004, EAI Industry Consortium: USA.

[17] Themistocleous, M., Justifying the Decision for EAI Implementations: A Validated Proposition of Factors. Journal of Enterprise Information Management, 2004. 17(2): p. 85104.

[18] Themistocleous, M. and G. Corbitt, Is Business Process Integration Feasible? Journal of Enterprise Information Management, 2005: p. In Press.

[19] Themistocleous, M. and Z. Irani, Benchmarking the Benefits and Barriers of Application Integration. Benchmarking: An International Journal, 2001. 8(4): p. 317-331.

[20] Themistocleous, M. and Z. Irani. Evaluating and Adopting Application Integration: The Case of a Multinational Petroleum Company. in Thirty-Fifth Annual Hawaii International Conference on System Sciences, (Hicss 35). 2002. Big Island, Hawaii, USA: IEEE Computer Society, Los Alamitos, California, USA.

[21] Themistocleous, M. and Z. Irani. Towards a Novel Framework for the Assessment of Enterprise Application Integration Packages. in ThirtySix Annual Hawaii International Conference on System Sciences, (Hicss 36). 2003. Big Island, Hawaii, USA: IEEE Computer Society, Los Alamitos, California, USA.

[22] Themistocleous, M., Z. Irani, and P.E.D. Love, Evaluating the Integration of Supply Chain
Information Systems: A Case Study. European Journal of Operational Research, 2004. 159(2): p. 393-405.

[23] Themistocleous, M., Z. Irani, and P.E.D. Love. Developing E-Government Integrated Infrastructures: A Case Study. in Thirty-Eight Annual Hawaii International Conference on System Sciences, (Hicss 38). 2005. Big Island, Hawaii, USA: IEEE Computer Society, Los Alamitos, California, USA.

[24] Themistocleous, M., Z. Irani, and A. Sharif. Evaluating Application Integration. in seventh European Conference on Evaluation of Information Technology (ECITE 2000). 2000. Dublin, Ireland: MCIL Reading UK.

[25] Themistocleous, M. and K. Khoumbati, Towards the Development of a Model for the Adoption of Integration Technologies. Journal of Intelligent Systems, 2005. In Press.

[26] Yin, R.K., Case Study Research: Design and Methods. 1994, California, USA: Sage Publications. 